\title{
APPLICATION OF A NEW HYBRIDIZATION TO SOLVE ECONOMIC DISPATCH PROBLEM ON AN ALGERIAN POWER SYSTEM WITHOUT OR WITH CONNECTION TO A RENEWABLE ENERGY
}

\author{
Abdelkader Si TAYEB ${ }^{1,2^{*}}$, Benyekhlef LAROUCI ${ }^{3}$, Daoud REZZAK ${ }^{1}$, Yehya HOUAM ${ }^{1}$, \\ Hamid BOUZEBOUDJA ${ }^{2}$, Abdelhak BOUCHAKOUR ${ }^{1}$ \\ ${ }^{1}$ Unité de Recherche Appliquée en Energies Renouvelables, URAER, Centre de Développement des Energies \\ Renouvelables, CDER, 47133, Ghardaïa, Alegria. si_tayeb12@yahoo.fr \\ ${ }^{2}$ Faculty of electrical engineering, USTO-MB. B.P 1505 El M'naouar, Oran, 31000, Algeria, Laboratory of Sustainable \\ Development of Electrical Energy LDDEE \\ ${ }^{3}$ Department of Electrical Engineering, Faculty of Applied Sciences, University Kasdi Merbah Ouargla, Street Ghardaia, \\ 30000, Ouargla, Algeria
}

Abstract

The most important contribution of this article is the use of four metaheuristic approaches to tackle the problem of economic dispatching, with the goal to study the influence of the injection of a renewable energy source on the electricity cost in the Algerian network, and minimizing the production cost of electrical energy while accounting for transmission losses.

A Genetic Algorithm (GA) (a real coding) and Egyptian Vulture Optimization Algorithm (EVOA), as well as two hybridizations between the metaheuristics: Classic and Modern hybridization (C.H.GA-EVOA, M.H.GA-EVOA), are presented in this work. These techniques are used to address optimization difficulties of two Algerian electricity networks. The first has three system units, whereas the second has fifteen system units. The second electricity network is connected to a solar energy source.

The findings obtained are compared with other techniques to validate the high performance of the suggested methods for addressing the economic dispatch issue. This study demonstrates that EVOA and C.H.GA-EVOA provide trustworthy results, and that M.H.GA-EVOA surpasses them.

Keywords: economic dispatching; Genetic Algorithm; Egyptian Vulture; Classic Hybridization; Modern Hybridization; solar energy.

\section{INTRODUCTION}

Electrical energy consumption is increasing rapidly, with global consumption having doubled on average over the last 10 years from the beginning of the nineteenth century. This has resulted in an increase in the length and complexity of electrical networks, forcing researchers in this sector to select the best feasible solutions [1-5].

To ensure that the network runs smoothly, we must address economic dispatch issues, which necessitate improving electrical energy management by lowering production costs while maintaining a balance between production and consumption [6-10].

Researchers are continuously creating algorithms that make it possible to program the production of power plants in an optimal method in order to fulfill these goals in the energy industry. Among these algorithms (CBA) chaotic bat algorithm [11] and (CSA) cuckooo search algorithm [12, 13], (PSO) particle swarm optimization, (CTLBO) chaotic teaching learningbased optimization [14], (KGMO) kinetic gas molecule optimization algorithm [15], (THS) tournament-based harmony search [16], (IA)
Immune Algorithm [17], (SOA) seeker optimization algorithm [18], (MGSO) modified group search optimizer [19], (MSOS) modified symbiotic organisms search [20], (GWO) grey wolf optimization [21], (HGWO) hybrid grey wolf optimizer [22], (CSO) crisscross optimization algorithm [23], (GA) genetic algorithm [24], and (MABC) modified artificial bee colony algorithm [25]. Some of these algorithms are based on mathematical optimization methods witch are continually improved in order to increase their performance so that they are exploited instantaneously at the dispatching level. In parallel, another family of methods based on linear programming and nonlinear programming has appeared [26].

The danger of convergence towards a local optimum is a drawback of these approaches, especially if the goal function is non-linear or the derivatives are difficult to compute.

In combinatorial optimization, many problems are often difficult to resolve in a manner that is accurate [27]. This is not due to a lack of mathematical knowledge, but rather to technical problems. So against these obstacles, it must resort 
to methods of approximation of the solution. We will not seek more to obtain necessarily the best solution but rather a solution of good quality obtained to reduce loses and cost [28-32].

We proposed the use of two original stochastic optimization methods, the Genetic Algorithms GA and the Egyptian Vulture Optimization Algorithm EVOA, as well as two hybridizations: Classic Hybridization (C.H.GA-EVOA) and Modern Hybridization (C.H.GA-EVOA) to overcome the complexity of the problem of adaptation and to reduce costs and losses (M.H.GA-EVOA).

This study suggested a novel hybridization of GA and EVOA that uses metaheuristics of combinatorial optimization to solve the problem of the optimal allocation of active powers in two Algerian electricity networks with/without connection to solar energy production units.

For the first time, we use the EVOA, a metaheuristic approach of combinatorial optimization, to reduce the cost of producing electrical energy.

Then, with the aid of Genetic Algorithms, we apply a second technique of artificial intelligence to minimize the cost of producing electrical energy by binary encoding and then Natural by actual coding. Then we will build hybridization between: a GA and an EVOA method witch exhibited robustness, accuracy, highest performance, high precision, high stability, and simplicity.

- The first direct hybrid algorithm is a direct combination of GA and the EVOA method. In a first phase the GA explore the research space with the aim of discovering sub-spaces and providing a coarse solution, namely a solution located inside the basin of attraction of the global minimum. In a second phase, EVOA uses the best solution provided by the GA as initial estimate and continues the search according to its own mode of exploitation; it is the classic hybridization (C.H.GA-EVOA)

- The second hybrid algorithm in a first phase, the GA and the EVOA explore in parallel the research space with the aim of discovering promoter subspaces and providing coarse solutions, namely solutions located within the attraction basin of the global minimum. In a second phase, EVOA and GA use the best solution provided by the two algorithms as initial estimates and continue the search according to its own mode of operation. This principle is repeated for all the number of iterations, it is the modern hybridization (M.H.GA-EVOA).

The proposed approach has been tested on a variety of test systems, including two Algerian electricity networks, the first of which has three system units and the second of which has fifteen. The second Algerian electricity network has been optimized without and with connection to a solar energy source, with simulation results obtained in MATLAB. The results show that genetic algorithms, EVOA, classic and current hybridization have a clear interest in achieving dependable convergence to a global optimum while minimizing overall costs.

Compared with other methods, the results obtained are better in terms of minimizing the cost function.

\section{PRINCIPLE OF ECONOMIC DISTRIBUTION OF POWERS}

The basic goal of economic dispatch is to determine the active power contribution from each group of the electrical system's output such that the overall cost of production is reduced for any load state. The cost of manufacturing a unit varies depending on the amount of electricity it produces. The overall cost of the fuel in an electro-energy system with multiple producing units is simply equal to the sum of the fuel costs of the various units, or:

We consider a production-transport network at $n$ node where we have ng unit nodes. The function of this network's total production cost is given by the following form. [8], [11], [14]:

$$
F_{\text {glob }}=\sum_{i=1}^{n g} F_{i}\left(P_{g i}\right)
$$

With:

$P_{\text {gi: }}$ Represents the active powers generated.

ng: Represents the number of nodes generators.

$F_{\mathrm{i}}\left(\mathrm{P}_{\mathrm{gi}}\right)$ : Represents the cost of production of the unit i.

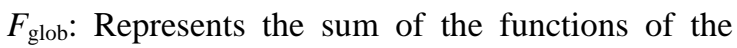
cost of each unit.

The problem of the economic distribution of powers is to minimize the function of the total cost of fuel necessary for the production of energy requested.

This function is given by a polynomial of degree (n) in the following general form:

$$
F\left(P_{\mathrm{g}}\right)=a_{0}+a_{1} P \mathrm{~g}+a_{2} P_{\mathrm{g}}^{2}+\ldots .+a_{\mathrm{n}} P_{\mathrm{g}}^{\mathrm{n}}
$$

The coefficients of the latter are computed using one of the interpolation methods, although in reality, this equation takes the form of a seconddegree polynomial, i.e.

$$
F_{\mathrm{i}}\left(P_{\mathrm{gi}}\right)=c_{\mathrm{i}}+b_{\mathrm{i}} P_{\mathrm{gi}}+a_{\mathrm{i}} P_{\mathrm{gi}}^{2} \ldots \ldots \ldots \ldots \ldots \ldots . . \mathrm{i}=1, \ldots ., \mathrm{ng}
$$

$a_{i}, b_{i}, c_{i}$ : Represents the coefficients of the cost function specific to the unit (i) [12], [25]. It is therefore, at this stage that the problem of the optimal allocation of powers arises, it can be represented as follows:

It is necessary to minimize the cost of electrical energy for the whole of units: 
$\operatorname{Min}\left\{F_{\text {glob }}\left(P_{\text {gi }}\right)=\sum_{\mathrm{i}=1}^{\mathrm{ng}} F_{\mathrm{i}}\left(P_{\mathrm{gi}}\right)\right\}$

Under the following constraints:

Equality constraints

$$
\sum_{\mathrm{i}=1}^{\mathrm{ng}} P_{\mathrm{gi}}=\sum_{i=1}^{n g} P_{\mathrm{D}}+P_{\mathrm{L}}
$$

The constraints of inequality

$P_{\mathrm{g} i}^{\min } \leq P_{\mathrm{g} i} \leq P_{\mathrm{g} i}^{\max }$

with:

$\mathrm{n}$ : Total number of nodes.

$P_{\text {gi }}$ : Active power produced by the ith unit node.

$P_{\mathrm{D}}$ : Active power consumed by ith load.

$P_{\mathrm{L}}$ : Losses total active in the network.

$P_{\mathrm{g} i}^{\max }$ : Maximum active power produced by ith unit.

$P_{\mathrm{g} i}^{\mathrm{min}}$ : Minimum active power produced by ith unit.

where $P_{\mathrm{D}}$ is the total power demand (system load)

and $P_{\mathrm{L}}$ is the total transmission loss.

The exact value of the transmission losses can only be obtained from a study of the power flow. Nevertheless, in studies of the economic dispatching, transmission losses are often expressed as a function of the active powers generated. This technique is commonly referred to as the $B$ coefficient method. In this approach, the losses are approximated by the Kron formula [30].

$$
P_{\mathrm{L}}=\sum_{\mathrm{i}=1}^{\mathrm{N}} \sum_{\mathrm{j}=1}^{\mathrm{N}} p_{\mathrm{i}} B_{\mathrm{ij}} p_{\mathrm{j}}
$$

where the terms $B_{\mathrm{ij}}$ are called coefficients of losses or coefficients $B$. The coefficients of the losses are not constant, but vary according to the operating conditions of the system. However, acceptable results can be obtained if the current operating conditions are relatively close to those for which the coefficients $B$ have been calculated [5].

\section{USED METAHEURISTICS METHODS}

\subsection{Description of EVOA}

The Egyptian vulture's optimization is based on the behavior of Egyptian vultures in quest of food, when they choose stones and hurl them with a probabilistic force and angle to break the eggs of other birds. The probabilistic decision that an Egyptian vulture singer makes to pick solutions evolves continually as the choice of stones, force, and angles of throwing stones changes [33].

This technique offered a combinatorial stochastic optimization strategy and demonstrated the speed of a novel method for finding acceptable solutions while avoiding premature convergences.

This method is versatile (it can be applied to similar versions of the same problem), robust and of course based on a population of individuals.

The EVOA algorithm is started with a random population of potential solutions, which are regarded as starting answers to the issues of food search in the search space. Each initial solution is drawn to its best choice discovery in the past, as well as the best decision discovery by its Neighborhood's first solutions. The EVOA algorithm has numerous adjustment factors that control the number of beginning values, the size of neighborhoods, and the precision with which the neighborhoods are created [34].

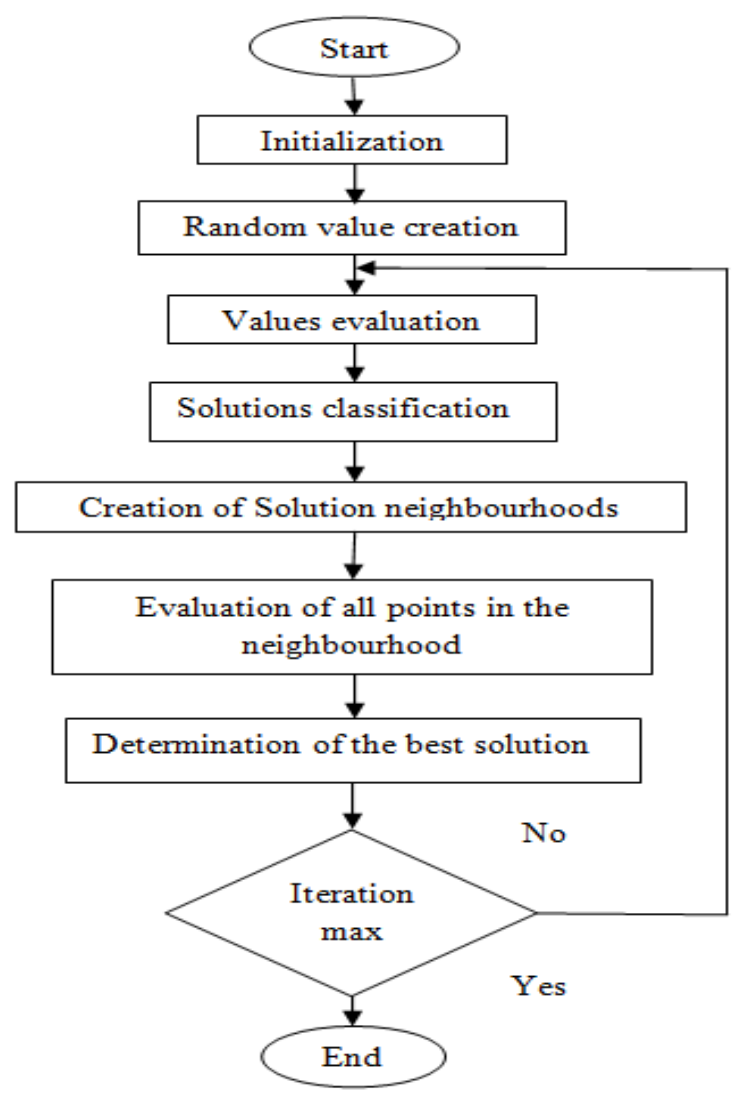

Fig.1. EVOA's organizational chart.

\subsection{Genetic Algorithms}

Genetic Algorithms, try to simulate the evolution process of a population. It part of a population $\mathrm{N}$ solutions of the problem presented by individuals. This population randomly chosen is called Initial. The adaptation degree of an individual to the environment is expressed by the value of the cost Function (Function Objective) $f(x)$, or $x$ is the solution that the individual represents.

It is said that an individual is much better adapted to its environment, when the cost of the solution that it represents is more low Within this population, then intervenes the random selection of one or two parents, who produce a new solution 
(new population), through the genetic operators, such that the crossing and the mutation. By iterating, this process produces a population, richer in individuals who are better adapted [35,36].

\subsection{The hybrid algorithms}

The most productive way of hybridization appears to be the mix of neighborhood methods [37], evolutionary approaches, and other methods. The basic concept behind this hybridization is to take advantage of the strength of neighborhood search and evolutionary algorithm recombination on a population of solutions. Without a doubt, hybrid algorithms are among the most effective approaches [38].

\subsubsection{Working principle of proposed hybridizations}

\section{Classic hybridization (C.H.GA-EVOA)}

The first direct hybrid algorithm is a direct combination of GA and the EVOA method. In a first phase the GA explore the research space with the aim of discovering sub-spaces and providing a coarse global solution, namely a solution located inside the basin of attraction of the global minimum [39]. In a second phase, EVOA uses the best solution provided by the GA as initial estimate and continues the search according to its own mode of exploitation. This combination of GA and EVOA is proposed to solve problems of creation of values initials, and to reduce computation time [40].

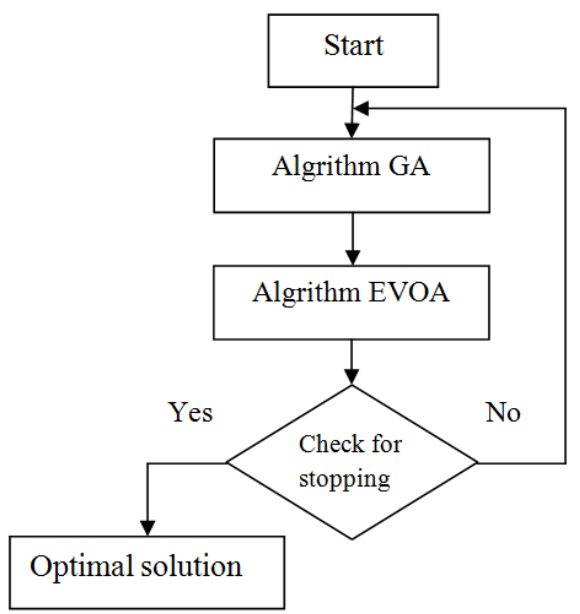

Fig. 2. Diagram representing classic hybridization (C.H.GA-EVOA) of GA and EVOA.

\section{Modern hybridization (M.H.GA-EVOA)}

The second hybrid algorithm, first, the GA and the EVOA explore in parallel the research space with the aim of discovering promoter subspaces and providing coarse solutions, namely solutions located within the attraction basin of the global minimum. In a second phase, EVOA and GA use the best solution as initial estimates and continue the search according to its own mode of operation.
This principle is repeated for all the number of iterations, it is the modern hybridization (M.H.GAEVOA).Therefore, this hybrid method, such as the combination of two methods, have been proposed to eliminate each method's drawback and Weak point

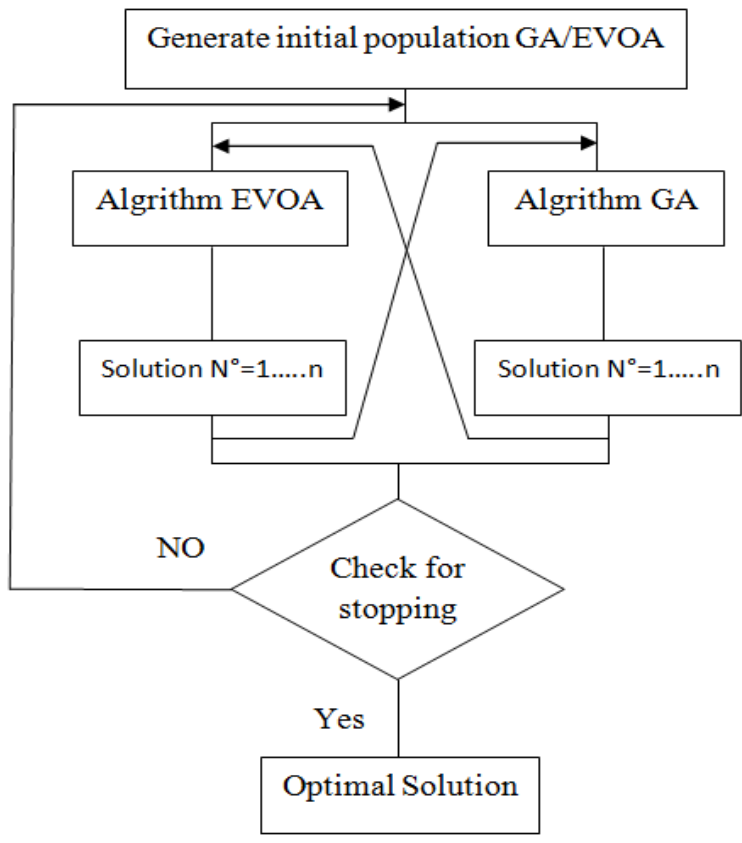

Fig. 3. Diagram representing modern hybridization (M.H.GA-EVOA) of GA and EVOA.

\section{RESULTS AND DISCUSSION}

\section{Application 1: A- electrical network without solar energy production unit}

The Algerian West $220 \mathrm{kV}$ network was used to test the system. Figure 4 shows a single-line schematic of the system. The system is made up of 14 nodes, including three generators: the "Mersa El Hadjadj" power plant (node 1), the "White Ravine" power plant (node 4) and the "Tiaret" unit (node 3) [41].

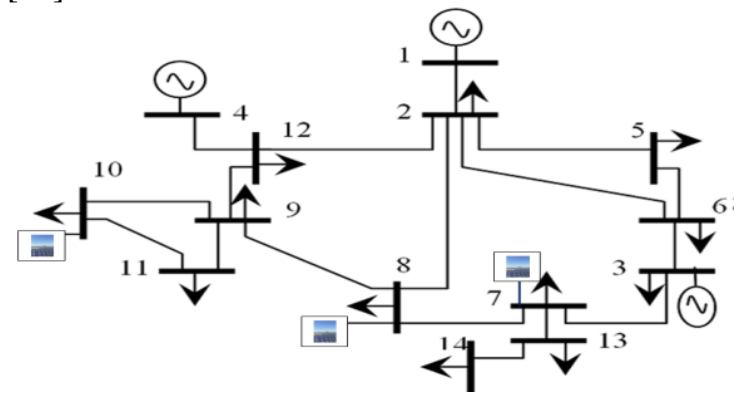

Fig.4. Topologie of the Algerian West Network connected to a renewable energy source

Table 1 group the coefficients of the cost functions providing the fuel quantity in $\mathrm{Nm} 3 / \mathrm{hr}$ including the minimum and maximum powers of each unit [41]. 
Si Tayeb A, Larouci B, Rezzak D, Houam Y, et al: Application of a new hybridization to solve economic ...

Table 1. data of three unit test system

\begin{tabular}{|c|c|c|c|c|c|}
\hline Unit & $P_{\mathrm{ig}}^{\max }$ & $P_{\mathrm{ig}}^{\mathrm{min}}$ & $\begin{array}{c}a_{i} \\
(\$ / M \\
\left.W^{2}\right)\end{array}$ & $\begin{array}{c}b_{i} \\
(\$ / M \\
W)\end{array}$ & $c_{i}(\$)$ \\
\hline $\begin{array}{c}\text { Mersat El } \\
\text { Hadjadj }\end{array}$ & 510 & 30 & 0.85 & 150 & 2000 \\
\hline Tiaret & 420 & 25 & 0.4 & 75 & 850 \\
\hline $\begin{array}{c}\text { Ravin } \\
\text { Blanc }\end{array}$ & 70 & 10 & 1.7 & 250 & 3000 \\
\hline
\end{tabular}

The coefficients of the transmission losses

$$
\begin{aligned}
& \mathrm{B}=1 \mathrm{e}-3 *[0.00546-0.000520 .00392 \\
& -0.000520 .01035-0.00137 \\
& 0.00392-0.001370 .001479]
\end{aligned}
$$

The powers generated optimal values of production and losses transmitted are grouped in table 2

Table 2. M.H.GA-EVOA compared with C.H.GAEVOA, GA and EVOA Methods for 3 units system

\begin{tabular}{|l|c|c|c|c|}
\hline Method & EVOA & GA & $\begin{array}{l}\text { C.H.GA- } \\
\text { EVOA }\end{array}$ & $\begin{array}{l}\text { M.H.GA- } \\
\text { VOA }\end{array}$ \\
\hline $\begin{array}{l}\text { Mersat } \\
\text { El } \\
\text { Hadjadj }\end{array}$ & 295.8071 & 294.2545 & 295.7052 & 295.6249 \\
\hline Tiaret & 420 & 420 & 420 & 420 \\
\hline $\begin{array}{l}\text { Ravin } \\
\text { Blanc }\end{array}$ & 68.4493 & 70 & 68.5517 & 68.6346 \\
\hline $\mathrm{P}_{\mathrm{D}}(\mathrm{MW})$ & 784.2565 & 784,2545 & 784.2569 & 784.2595 \\
\hline $\mathrm{P}_{\mathrm{L}}(\mathrm{MW})$ & 2.2574 & 2.2547 & 2.2693 & 2.2594 \\
\hline $\begin{array}{l}\text { cost } \\
(\$ / \mathrm{h})\end{array}$ & 251736.145 & 251477.237 & 251718.782 & 251705.595 \\
\hline
\end{tabular}

The best fuel cost result obtained from the proposed methods EVOA, GA, C.H.GA-EVOA, and M.H.GA-EVOA is compared in Table 2, which shows that the proposed methods EVOA, GA, C.H.GA-EVOA, and M.H.GA-EVOA clearly minimized the cost and that the M.H.GA-EVOA has an approximately good solution for the power demand of $782 \mathrm{MW}$.

Figures 5 and 6 show the convergence characteristics of M.H.GA-EVOA and C.H.GAEVOA in the search for the optimal generation cost over 70 iterations. We can see that the two techniques, M.H.GA-EVOA and C.H.GA-EVOA, converge fast towards the global optimum, with M.H.GA-EVOA providing the best result.

The first test of optimization (Figure 5) depicts the M.H.GA-EVOA convergence characteristic in the search for the best cost for a three-generator system with $\mathrm{PD}=782 \mathrm{MW}$. The graphic clearly shows that the solution converges to a high quality solution at an early iteration (10 iterations) and that the fuel cost function value does not change rapidly after 70 iterations.

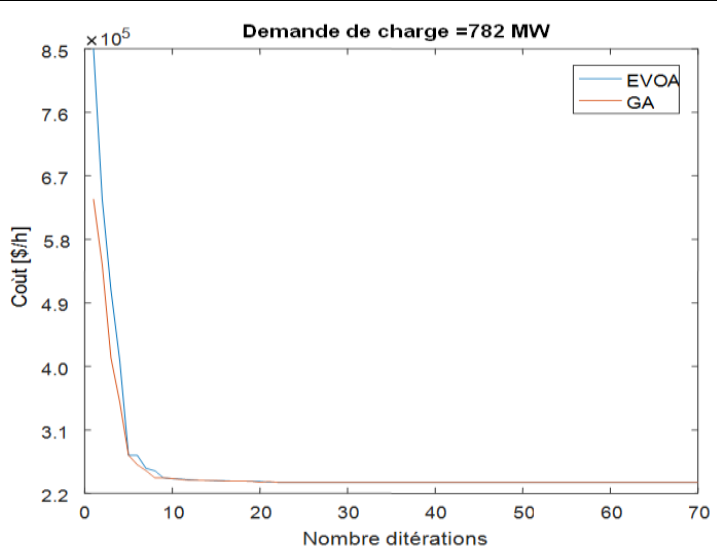

Fig. 5. Convergence characteristic of M.H.GA-EVOA for three generating unit system for $\mathrm{P}_{\mathrm{D}}=782 \mathrm{MW}$.

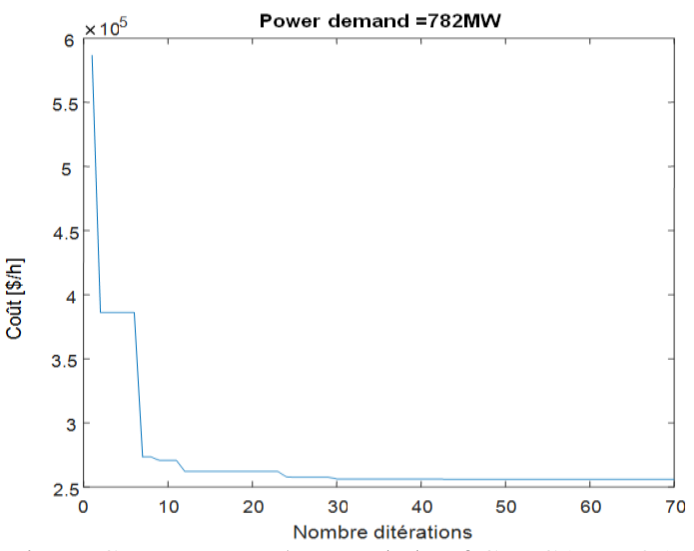

Fig. 6. Convergence characteristic of C.H.GA-EVOA for three generating unit system for $\mathrm{P}_{\mathrm{D}}=782 \mathrm{MW}$.

The convergence characteristic of C.H.GAEVOA in the search for the optimal cost for a threegenerating-unit system with $\mathrm{PD}=782 \mathrm{MW}$ is shown in Figure 6. The figure clearly shows that the solution is converged to a high quality solution at an early iteration (29 iterations) and that the fuel cost function value does not vary rapidly after 70 iterations.

\section{$B$ - electrical network with solar energy production unit}

This application, is interested in the economic dispatching solution with the integration of a solar center.

Table 3. West Algerian installed capacity renewable energies

\begin{tabular}{|c|c|}
\hline Renewable Energy unit & $\begin{array}{c}\text { Power installed } \\
\text { (MW) }\end{array}$ \\
\hline SedretLeghzel(Naâma) & 20 \\
\hline Ain Skhouna(Saida) & 30 \\
\hline Telagh(Sidi-Bel-Abbes) & 12 \\
\hline LabiodhSidi Chikh(El-Bayadh) & 23 \\
\hline
\end{tabular}

The first test of optimization Figure 7 depicts the M.H.GA-EVOA convergence characteristic when searching for the lowest cost for a three-generator system with $\mathrm{PD}=782 \mathrm{MW}$. The graphic clearly shows that the solution is converged to a high quality solution at an early iteration (50 iterations) 
Si Tayeb A, Larouci B, Rezzak D, Houam Y, et al: Application of a new hybridization to solve economic ...

Table 4. Optimization results of the methods proposed for a western Algerian network connected with renewable energy

\begin{tabular}{|c|c|c|c|c|}
\hline Method & EVOA & GA & C.H.GA-EVOA & M.H.GA-EVOA \\
\hline Mersat El Hadjadj & 247.1798 & 277.5990 & 214.1616 & 209.2342 \\
\hline Tiaret & 419.8988 & 377.5597 & 420 & 420 \\
\hline Ravin Blanc & 32.1227 & 44.3062 & 65.1486 & 70 \\
\hline SedretLeghzel(Naâma) & 20 & 20 & 20 & 20 \\
\hline Ain Skhouna(Saida) & 30 & 30 & 30 & 30 \\
\hline Telagh(Sidi-Bel-Abbes) & 12 & 12 & 12 & 12 \\
\hline LabiodhSidi Chikh(El-Bayadh) & 23 & 23 & 23 & 23 \\
\hline P $_{\mathrm{D}}(\mathrm{MW})$ & 784.2013 & 784.4649 & 784.2342 & 784.3102 \\
\hline PL $_{\mathrm{L}}(\mathrm{MW})$ & 2.2013 & 2.4649 & 2.2342 & 2.3102 \\
\hline Cost $(\$ / \mathrm{h})$ & 206697.2176 & 213165.2986 & 202548.0333 & 202343.6388 \\
\hline
\end{tabular}

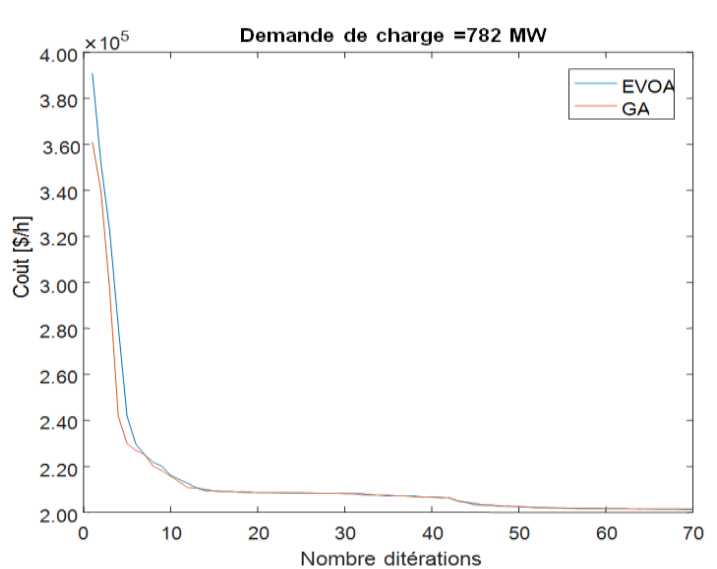

Fig.7. Convergence characteristic of M.H.GA-

EVOA for a system of 7 generators for $\mathrm{PD}_{\mathrm{D}}=782$ MW.

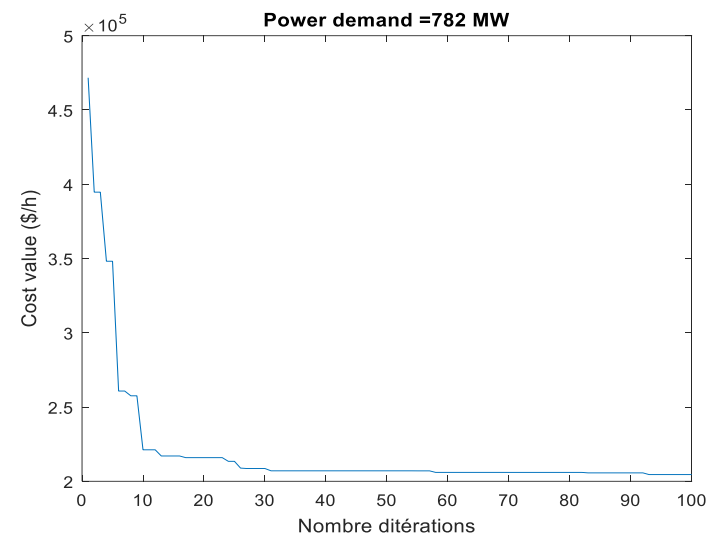

Fig. 8. Convergence characteristic of C.H.GA-EVOA for a system of 7 generators for $\mathrm{P}_{\mathrm{D}}=782 \mathrm{MW}$. and that the fuel cost function value does not vary rapidly after 70 iterations.

\section{Application 2 : A- electrical network without solar energy production unit}

The Algerian network characteristics are presented in Table 5 [42]. In this case, the optimization was applied to a dynamic economic dispatch problem with ramping limits constraints of the Algerian 114 bus power plan with 9 classic generators, the total load for 10 time periods of the system is given in table 5 , the unit data of this system is given in table 6 , and the coefficient are calculated directly with the power flow results.

Table 5. The total Load for 10 time period

\begin{tabular}{|c|c|c|}
\hline $\begin{array}{c}\text { Time from } \\
\text { (h) }\end{array}$ & time to (h) & $\begin{array}{c}\text { Power } \\
\text { Demand } \\
\text { (MW) }\end{array}$ \\
\hline 1 & 2 & 2500 \\
\hline 2 & 3 & 3000 \\
\hline 3 & 4 & 3727 \\
\hline 4 & 5 & 4500 \\
\hline 5 & 6 & 4800 \\
\hline 6 & 7 & 5500 \\
\hline 7 & 8 & 5000 \\
\hline 8 & 9 & 4100 \\
\hline 9 & 10 & 3200 \\
\hline
\end{tabular}

Table 7. M.H.GA-EVOA compared with C.H.GA-EVOA, GA and EVOA Methods for Algerian network Pch=3727MW without.

\begin{tabular}{|c|c|c|c|c|}
\hline Unit (MW) & M.H.GA-EVOA & C.H.GA-EVOA & EVOA & GA \\
\hline Pg_4 & 478.1326 & 437.2393 & 438.9471 & 465.9004 \\
\hline Pg_5 & 460.3928 & 505.4518 & 453.9453 & 445.3410 \\
\hline Pg_11 & 99.9996 & 100 & 99.9832 & 99.9967 \\
\hline Pg_15 & 192.5093 & 153.8415 & 156.5098 & 186.7848 \\
\hline Pg_17 & 478.5429 & 414.1632 & 456.5655 & 433.0336 \\
\hline Pg_19 & 188.2747 & 207.6052 & 201.6767 & 196.1141 \\
\hline Pg_52 & 195.6971 & 205.8742 & 205.1403 & 179.2467 \\
\hline Pg_22 & 178.6094 & 211.5898 & 239.5093 & 181.2029 \\
\hline
\end{tabular}


Si Tayeb A, Larouci B, Rezzak D, Houam Y, et al: Application of a new hybridization to solve economic ...

\begin{tabular}{|c|c|c|c|c|}
\hline Pg_80 & 192.5800 & 196.2930 & 180.0636 & 197.5288 \\
\hline Pg_83 & 183.2387 & 192.0625 & 222.5353 & 276.9284 \\
\hline Pg_98 & 180.8297 & 204.6862 & 176.1976 & 168.2754 \\
\hline Pg_100 & 599.9835 & 600 & 600 & 599.9702 \\
\hline Pg_101 & 200 & 200 & 200 & 199.995 \\
\hline Pg_109 & 99.9554 & 100 & 97.6374 & 99.9715 \\
\hline Pg_111 & 99.9068 & 99.8419 & 99.9339 & 98.3595 \\
\hline Total output & 3828.6531 & 3828.649 & 3828.645 & 3828.649 \\
\hline PL & 101.6531 & 101.649 & 101.645 & 101.649 \\
\hline cost $(\$ / h)$ & 19338.705 & 19389.89 & 19404.58 & 19456.07 \\
\hline
\end{tabular}

Table 6. Generating unit data for 15 units system.

\begin{tabular}{|c|c|c|c|c|c|}
\hline Unit & $P_{\mathrm{ig}}^{\min }$ & $P_{\mathrm{ig}}^{\max }$ & $a_{i}\left(\$ / M W^{2}\right)$ & $b_{i}(\$ / M W)$ & $c_{i}(\$)$ \\
\hline 1 & 135 & 1350 & 0.0085 & 1.5000 & 0 \\
\hline 2 & 135 & 1350 & 0.0085 & 1.5000 & 0 \\
\hline 3 & 10 & 100 & 0.0170 & 2.5000 & 0 \\
\hline 4 & 30 & 300 & 0.0170 & 2.5000 & 0 \\
\hline 5 & 135 & 1350 & 0.0085 & 1.5000 & 0 \\
\hline 6 & 34.5 & 345 & 0.0170 & 2.5000 & 0 \\
\hline 7 & 34.5 & 345 & 0.0170 & 2.5000 & 0 \\
\hline 8 & 34.5 & 345 & 0.0170 & 2.500 & 0 \\
\hline 9 & 34.5 & 345 & 0.0170 & 2.5000 & 0 \\
\hline 10 & 30 & 300 & 0.0170 & 2.5000 & 0 \\
\hline 11 & 30 & 300 & 0.0170 & 2.5000 & 0 \\
\hline 12 & 60 & 600 & 0.0030 & 2.0000 & 0 \\
\hline 13 & 20 & 200 & 0.0030 & 2.0000 & 0 \\
\hline 14 & 10 & 100 & 0.0170 & 2.5000 & 0 \\
\hline 15 & 10 & 100 & 0.0170 & 2.5000 & 0 \\
\hline
\end{tabular}

Table 7 shows the optimal cost results using M.H.GA-EVOA, C.H.GA-EVOA, GA and EVOA with consideration of losses, the best cost obtained is $19338.7050(\$ / \mathrm{h})$ found by M.H.GA-EVOA.

From the results indicated in Table 8 it can be clearly seen that M.H.GA-EVOA and C.H.GAEVOA reduce the total cost and loses compared with GA, EVOA, PSO, FA, BA and HYB.

Table 8. Comparison of the M.H.GA-EVOA, C.H.GAEVOA, GA and EVOA with different evolutionary methods for Algerian network.

\begin{tabular}{|l|c|c|}
\hline $\begin{array}{c}\text { The algorithms } \\
\text { used }\end{array}$ & Total output & Total Cost $(\$ / \mathrm{h})$ \\
\hline M.H.GA-EVOA & 3828.6531 & 19338.7050 \\
\hline C.H.GA-EVOA & 3828.6492 & 19389.8918 \\
\hline EVOA & 3828.64566 & 19404.5899 \\
\hline GA & 3828.64955 & 19456.0767 \\
\hline PSO [42 ] & 3833.362 & 19442,08 \\
\hline FA [43] & 3831.5453 & 19445.51 \\
\hline BA [43] & 3830.9054 & 19439.99 \\
\hline HYB [43] & 3830.2206 & 19441.80 \\
\hline
\end{tabular}

Figure 9 shows the convergence characteristic of M.H.GA-EVOA, while Figure 15 shows the convergence characteristic of C.H.GA-EVOA in the search for the optimal generation cost over 70 iterations. We can see that both methods, M.H.GAEVOA and C.H.GA-EVOA, converge quickly towards the global optimum, with M.H.GA-EVOA providing the best result.

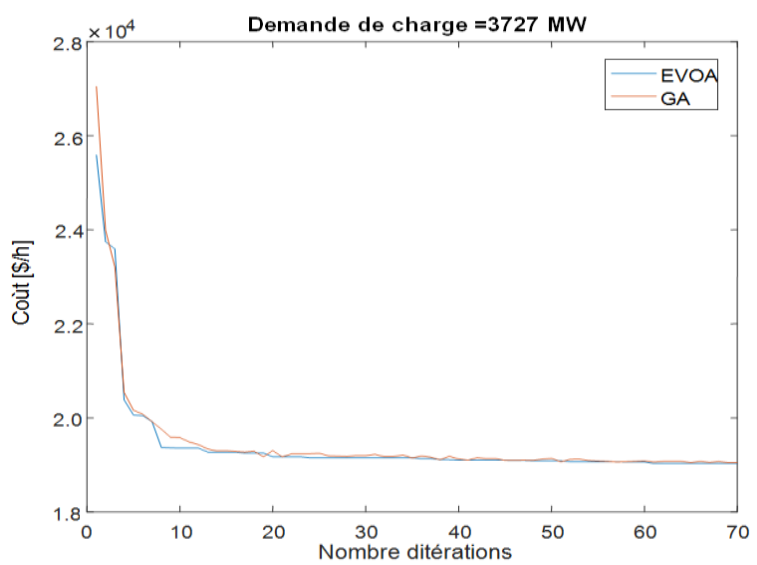

Fig. 9. Convergence characteristic of M.H.GA-EVOA for Algerian network for $\mathrm{P}_{\mathrm{D}}=3727 \mathrm{MW}$.

Table 9 compares the costs of variable loads in a 15-unit network. The charges are as follows: 2500 ,

The first test of optimization, Figure 9, shows the convergence characteristic of M.H.GA-EVOA in search of the optimum cost for three generating unit system for $P_{D}=3727 \mathrm{MW}$. It was clearly shown from the figure that the solution is converged to a high quality solution at early iterations (50 iterations) and that there is no rapid change in the fuel cost function value after 70 iterations.

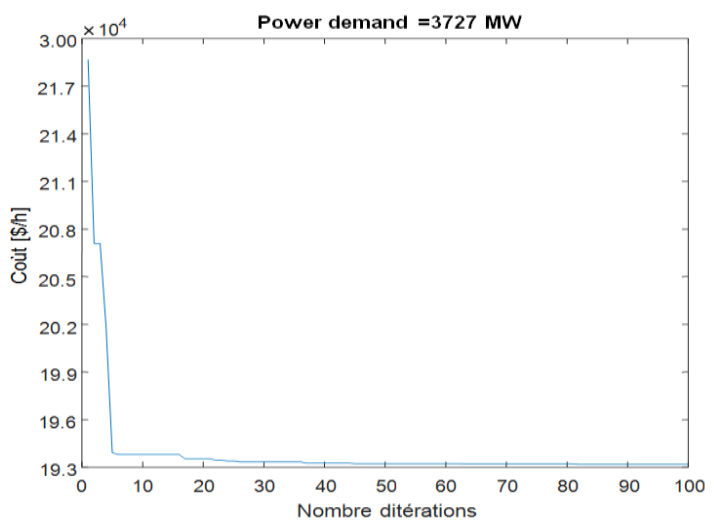

Fig. 10. Convergence characteristic of C.H.GA-EVOA for Algerian network for $\mathrm{P}_{\mathrm{D}}=3727 \mathrm{MW}$. 
Si Tayeb A, Larouci B, Rezzak D, Houam Y, et al: Application of a new hybridization to solve economic ...

Table 9. Economic dispatch results of variable loads for 15 units system.

\begin{tabular}{|c|c|c|c|c|c|c|c|c|}
\hline \multirow{2}{*}{$\begin{array}{c}\text { Total } \\
\text { Load }\end{array}$} & \multicolumn{9}{|c|}{ M. H.GA-EVOA } & \multicolumn{2}{|c|}{ C. H.GA-EVOA } & \multicolumn{2}{c|}{ EVOA } & \multicolumn{3}{c|}{ GA } \\
\cline { 2 - 10 } & Total output & cost $(\$ / \mathrm{h})$ & Total output & cost $(\$ / \mathrm{h})$ & Total output & cost $(\$ / \mathrm{h})$ & Total output & cost $(\$ / \mathrm{h})$ \\
\hline 2500 & 2558.09435 & 9765.26198 & 2558.09332 & 9782.44249 & 2558.0941 & 9789.9813 & 2558.09332 & 9782.44249 \\
\hline 3000 & 3073.40636 & 13131.7119 & 3073.40642 & 13136.0679 & 3073.40582 & 13174.764 & 3073.40793 & 13402.2778 \\
\hline 3727 & 3828.6531 & 19338.7050 & 3828.6492 & 19389.8918 & 3828.64566 & 19404.5899 & 3828.64955 & 19456.0767 \\
\hline 4500 & 4626.3649 & 27517.1337 & 4626.3646 & 27596.8046 & 4626.3668 & 27600.8055 & 4626.3671 & 27620.5074 \\
\hline 4800 & 4991.7743 & 31765.604 & 4991.7747 & 31776.1741 & 4991.7756 & 31808.2059 & 4991.78244 & 31825.1459 \\
\hline 5500 & 5786.5298 & 42615.2437 & 5786.5224 & 42723.5746 & 5786.5187 & 42770.8054 & 5786.5218 & 42782.597 \\
\hline 5000 & 5214.4985 & 34582.7541 & 5214.5006 & 34628.6399 & 5214.4914 & 34633.7739 & 5214.5035 & 34637.0485 \\
\hline 4100 & 4230.8281 & 23214.6811 & 4230.8277 & 23238.3823 & 4230.8165 & 23281.5083 & 4230.8314 & 23311.3722 \\
\hline 3200 & 3280.50188 & 14677.1314 & 3280.50474 & 14688.6769 & 3280.51312 & 14690.4698 & 3280.50528 & 14701.9662 \\
\hline
\end{tabular}

The convergence characteristic of C.H.GAEVOA in the search for the optimal cost for a 15 generating unit system with $\mathrm{P}_{\mathrm{D}}=3727 \mathrm{MW}$ is shown in Figure 10. The graphic clearly shows that the solution is converged to a high quality solution at an early iteration (45 iterations) and that the fuel cost function value does not vary rapidly after 100 iterations. clearly show that M.H.GA-EVOA reduced the cost regardless of the load.

Table 9 where the charges are successively as 3000, 3727, 4500, 4800, 5500, 5000, 4100, and $3200 \mathrm{MW}$. The suggested techniques EVOA, GA, C.H.GA-EVOA, and M.H.GA-EVOA are compared in this study. The results in Table 9 clearly show that M.H.GA-EVOA reduced the cost regardless of the load.

\section{B- electrical network with solar energy production unit}

This application, is interested in the economic dispatching solution with the integration of a solar units.

We note that the solar units (Table.10) are located in Algeria so that theese solar units operate and generate around $266.1 \mathrm{MW}$, and connected to the Algerian power system [42, 43].

In this test system, we have applied the methods EVOA, GA, C.H.GA-EVOA and M.H.GA-EVOA in order to improve the function total cost. The application is made on 9 different loads.

Table 10. Renewable energy units installed in Algeria

\begin{tabular}{|l|c|}
\hline \multicolumn{1}{|c|}{ Renewable Energy unit } & $\begin{array}{c}\text { Power installed } \\
\text { (MW) }\end{array}$ \\
\hline Oued Nechou PV (Ghardaia) & 1.1 \\
\hline SedretLeghzel (Naâma) & 20 \\
\hline Oued El kebrit (Souk Ahras) & 15 \\
\hline Ain Skhouna (Saida) & 30 \\
\hline Ain El Bel (Djelfa) 1 et 2 & 53 \\
\hline Lekhneg (Laghouat) 1 et 2 & 60 \\
\hline Telagh (Sidi-Bel-Abbes) & 12 \\
\hline $\begin{array}{l}\text { LabiodhSidi Chikh (El- } \\
\text { Bayadh) }\end{array}$ & 23 \\
\hline El Hdjira (Ouargla) & 30 \\
\hline Ain-El-Melh (M'Sila) & 20 \\
\hline OuedEl Ma (Batna) & 02 \\
\hline
\end{tabular}

The obtained findings show that the suggested approaches have a certain interest in terms of dependable convergence toward a global optimum and decreased overall cost reduction. When compared to EVOA, GA, C.H.GA-EVOA, and other approaches, the M.H.GA-EVOA method converges faster.

Table 11 compares the best fuel cost results derived from the suggested techniques EVOA, GA, C.H.GA-EVOA, and M.H.GA-EVOA, as well as other optimization algorithms, showing that the proposed methods EVOA, GA, C.H.GA-EVOA, and M.H.GA-EVOA clearly minimized the cost. When compared to other optimization methods, the M. H GA-EVOA provides a rather excellent answer for the $3727 \mathrm{MW}$ power requirement.

Figure 11 depicts the M.H.GA-EVOA convergence characteristic in the search for the best cost for a 26-generator system with $\mathrm{PD}=3727 \mathrm{MW}$. The figure clearly shows that the solution is converged to a high quality solution at early iterations (18 iterations) and that the fuel cost function value does not vary rapidly after 70 iterations.

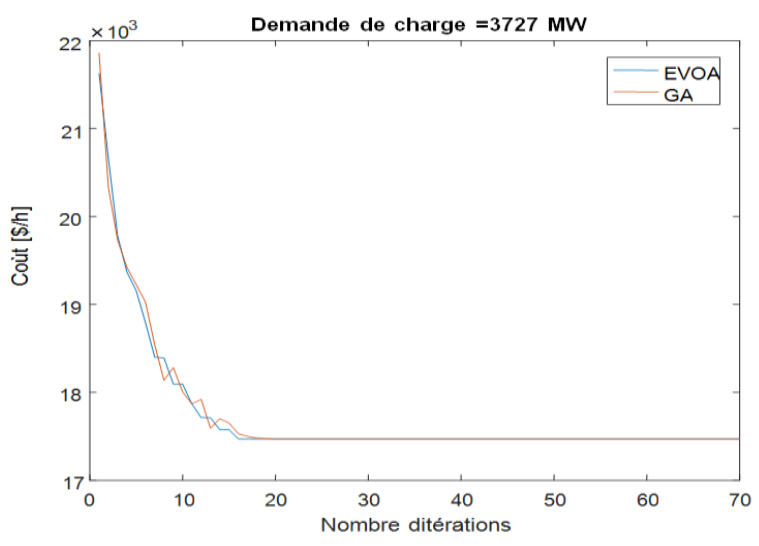

Fig.11. Convergence characteristic of M.H.GA-EVOA for Algerian network for $\mathrm{P}_{\mathrm{D}}=3727 \mathrm{MW}$.

Figure 11 shows the convergence characteristic of M.H.GA-EVOA in search of the optimum cost for 26 generating unit system for $\mathrm{P}_{\mathrm{D}}=3727 \mathrm{MW}$. It was clearly shown from the figure that the solution is converged to a high quality solution at early 
Si Tayeb A, Larouci B, Rezzak D, Houam Y, et al: Application of a new hybridization to solve economic ...

Table 11. Comparison of proposed methods for Algerian network connected to solar units

\begin{tabular}{|c|c|c|c|c|}
\hline Unit (MW) & M.H.GA-EVOA & C.H.GA-EVOA & EVOA & GA \\
\hline Pg_4 & 407.8376 & 595.6580 & 593.5651 & 509.9105 \\
\hline Pg_5 & 564.6554 & 255.1066 & 365.6622 & 291.1171 \\
\hline Pg_11 & 67.8266 & 88.8250 & 44.6844 & 73.8813 \\
\hline Pg_15 & 137.6606 & 197.2694 & 225.7023 & 95.9382 \\
\hline Pg_17 & 379.4056 & 440.1205 & 528.2573 & 404.1019 \\
\hline Pg_19 & 162.3120 & 167.9163 & 89.0690 & 291.1748 \\
\hline Pg_52 & 140.0823 & 260.1457 & 178.6339 & 154.3353 \\
\hline Pg_22 & 129.2858 & 188.0164 & 131.1582 & 185.3904 \\
\hline Pg_80 & 247.5282 & 126.7413 & 78.2766 & 222.8013 \\
\hline Pg_83 & 209.5447 & 151.6242 & 261.1066 & 238.4779 \\
\hline Pg_98 & 144.5444 & 172.6281 & 114.9896 & 256.0692 \\
\hline Pg_100 & 600 & 577,8229 & 600 & 600 \\
\hline Pg_101 & 199.7370 & 169.6443 & 198.1409 & 200 \\
\hline Pg_109 & 73.2989 & 84.4052 & 75.0135 & 10 \\
\hline Pg_111 & 98.6178 & 86.4112 & 78.0783 & 29.2773 \\
\hline PV (Ghardaia) & 1.1 & 1.1 & 1.1 & 1.1 \\
\hline PV (Naâma) & 20 & 20 & 20 & 20 \\
\hline PV (Souk Ahras) & 15 & 15 & 15 & 15 \\
\hline PV (Saida) & 30 & 30 & 30 & 30 \\
\hline PV (Djelfa)1 et 2 & 53 & 53 & 53 & 53 \\
\hline PV (Laghouat)1 et 2 & 60 & 60 & 60 & 60 \\
\hline PV (Sidi-Bel-Abbes) & 12 & 12 & 12 & 12 \\
\hline PV (El-Bayadh) & 23 & 23 & 23 & 23 \\
\hline PV (Ouargla) & 30 & 30 & 30 & 30 \\
\hline PV (M'Sila) & 20 & 20 & 20 & 20 \\
\hline PV (Batna) & 02 & 17989.8154 & 18277.2698 & 18630.8913 \\
\hline Total output & 3828.4376 & & & 02 \\
\hline PL & 101.4376 & 17567.1261 & 3828.4387 & 3828.5757 \\
\hline cost (\$/h) & & 3828.4387 & 3828.5757 \\
\hline & & & & \\
\hline & & & & \\
\hline
\end{tabular}

Table 12. Economic dispatch results of variable loads for 15 units system connected 11 solar units.

\begin{tabular}{|c|c|c|c|c|c|c|c|c|}
\hline \multirow{2}{*}{$\begin{array}{c}\text { Total } \\
\text { Load }\end{array}$} & \multicolumn{9}{|c|}{ M.H.GA-EVOA } & \multicolumn{2}{c|}{ C. H.GA-EVOA } & \multicolumn{2}{|c|}{ EVOA } & \multicolumn{2}{|c|}{ GA } \\
\cline { 2 - 9 } & $\begin{array}{c}\text { Total } \\
\text { output }\end{array}$ & cost $(\$ / \mathrm{h})$ & $\begin{array}{c}\text { Total } \\
\text { output }\end{array}$ & cost $(\$ / \mathrm{h})$ & Total output & cost $(\$ / \mathrm{h})$ & $\begin{array}{c}\text { Total } \\
\text { output }\end{array}$ & cost $(\$ / \mathrm{h})$ \\
\hline 2500 & 2557.4992 & 8807.8791 & 2557.4948 & 9002.6914 & 2557.5099 & 9104.9572 & 2557.4954 & 9231.3657 \\
\hline 3000 & 3070.1346 & 11643.7079 & 3070.1069 & 11965.4191 & 3070.1021 & 12158.3196 & 3070.1084 & 12414.2895 \\
\hline 3727 & 3828.4376 & 17567.1260 & 3828.4358 & 17989.8154 & 3828.4387 & 18277.2698 & 3828.5757 & 18630.8912 \\
\hline 4500 & 4655.1971 & 25248.0293 & 4655.1944 & 26181.7111 & 4655.2050 & 26428.3932 & 4655.2053 & 26828.5993 \\
\hline 4800 & 4982.6792 & 29051.5304 & 4982.7098 & 30345.5475 & 4982.7652 & 30430.5097 & 4982.7136 & 31171.9672 \\
\hline 5500 & 5773.8139 & 39938.50545 & 5773.8327 & 40065.7755 & 5773.812293 & 41253.8539 & 5773.8326 & 42537.7766 \\
\hline 5000 & 5204.8244 & 32819.9047 & 5204.7926 & 33155.7217 & 5204.8230 & 33382.6388 & 5204.8144 & 33589.2335 \\
\hline 4100 & 4225.1666 & 21710.7576 & 4225.1935 & 22028.6917 & 4225.1683 & 22192.3119 & 4225.1928 & 22416.4079 \\
\hline 3200 & 2557.5033 & 8648.5321 & 2557.4978 & 8745.0599 & 2557.4977 & 8791.2864 & 2557.5158 & 8889.6479 \\
\hline
\end{tabular}

iterations (18 iterations) and that there is no rapid change in the fuel cost function value after 70 iterations.

In order to improve the function total cost, we used the techniques EVOA, GA, C.H.GA-EVOA, and M.H.GA-EVOA in this test system. The software is tested on nine different loads.

The obtained findings show that the suggested approaches have a certain interest in terms of dependable convergence toward a global optimum and decreased overall cost reduction. When compared to EVOA, GA, C.H.GA-EVOA, and other approaches, the M.H.GA-EVOA method converges faster.

Figure 12 shows the convergence characteristic of C.H.GA-EVOA in search of the optimum cost for 26 generators unit system for $\mathrm{P}_{\mathrm{D}}=3727 \mathrm{MW}$. It was clearly shown from the figure that the solution is converged to a high quality solution at early iterations (28 iterations) and that there is no rapid change in the fuel cost function value after 70 iterations. 


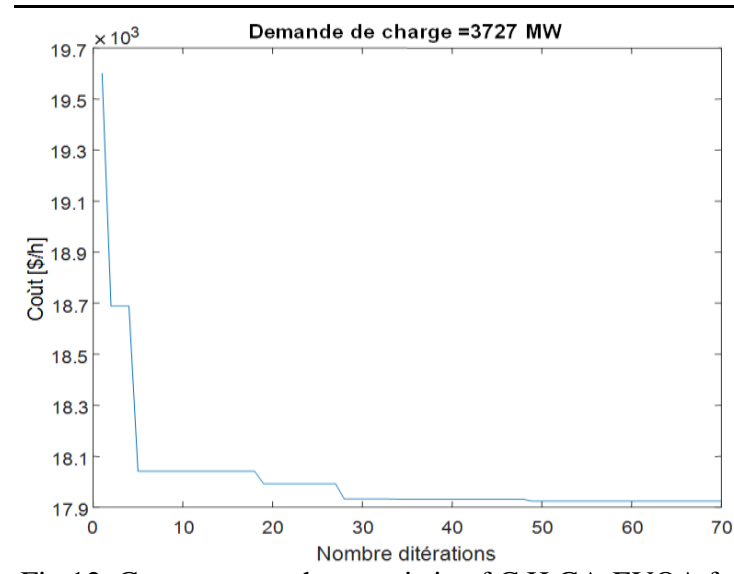

Fig.12. Convergence characteristic of C.H.GA-EVOA for Algerian network for $\mathrm{P}_{\mathrm{D}}=3727 \mathrm{MW}$.

A comparison of the cost in the case of variable loads in a network of 26 units system is shown in

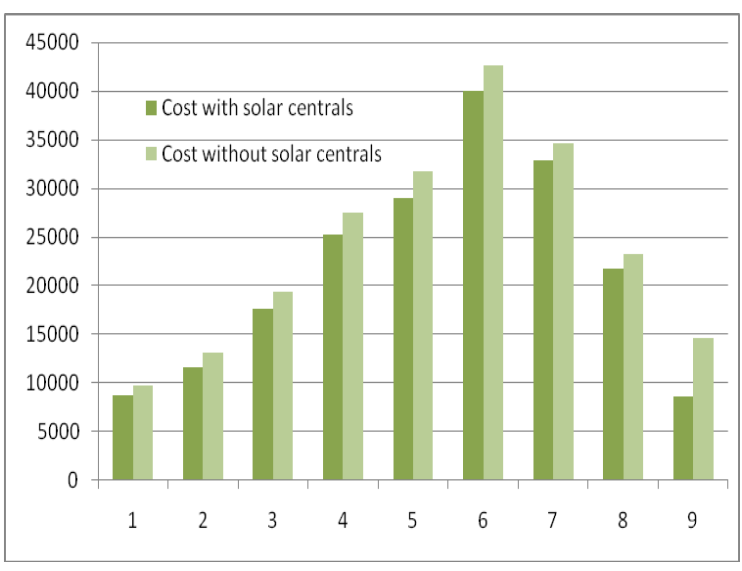

Fig.13. Comparaison of the cost obtained by M.H.GAEVOA in power system without and with connection to solar units.

Note: Figure 13. Shows that the cost is better minimized when the power system is connected to solar units.

\section{Conclusion}

This study makes a contribution to the solution of the problem of economic dispatching; four techniques were investigated to address the problem.

In order to address the minimization of the objective function, the employment of these approaches in the optimum distribution of active powers necessitates a thorough evaluation of the various parameters.

The four algorithms, namely (GA), (EVOA), and the hybrid algorithm (C.H.GA-EVOA), as well as the hybrid algorithm in its developed version (M.H.GA-EVOA), were applied on two Algerian electricity networks, the first of which contains 7 system units and the second of which contains 26 system units. The Algerian electricity network was optimized without or with connections.
The results of the metaheuristic approaches used (GA), (EVOA) are of particular relevance in terms of dependable convergence toward loss minimization and total cost minimization. The capacity of metaheuristic strategies to reach the optimal value of the cost of production is demonstrated by a comparison of results acquired from metaheuristic techniques. The most successful approach is always the EVOA method.

The results show that when the electrical network is connected to renewable energy production units, the cost function is better reduced

\section{REFERENCES}

1. Irina $\mathrm{C}$, Elias $\mathrm{K}$. Recent methodologies and approaches for the economic dispatch of generation in power systems. Int trans Electr Energ Syst. 2013;23:1002-27.

https:// doi: $10.1002 /$ etep.1635

2. Belkacem M, Kamel S. Interactive gravitational search algorithm and pattern search algorithm s for practical dynamic economic dispatch. Int $\mathrm{T}$ Electr Energy. 2015; 25:2289-09.

3. Si Tayeb, A. Bouzeboudja, H. Laroussé B, Naama B, Rezzak D. Egyptian Vulture Optimization For Combined Economic and Emission Dispatch New Meta- heuristic Algorithm. Journal of Electrical Engineering. 2017 17: 4-54.

4. Haiwang Z, Qing X, Yang W, Chongqing K. Dynamic economic dispatch considering transmission losses using quadratically constrained quadratic Program method. Power Syst IEEE Trans. 2013; 28(3):2232-41

https:// doi: 10.1109/TPWRS.2013.2254503

5. BOUALLAG K, DJEKIDEL R, BESSEDIK S. Optimisation de la tension induite sur une canalisation enterrée à partir de lignes électriques HT à l'aide de l'algorithme Grasshopper (GOA). DIAGNOSTYKA.2021;22(2):105-115. https://doi.org/10.29354/diag/138719

6. Ding T, Bo R, Li F, Sun H. A Bi-Level branch and bound method for economic dispatch with disjoint prohibited zones considering network losses. IEEE Trans Power Syst. 2015;30 (6):2841-55.

https://doi : 10.1109/TPWRS.2014.2375322

7. Ehsan A, Mahmood J. An improved cuckoo search algorithm for power economic load dispatch" Int T Electr Energy. 2015; 25:958-75. https://doi : 10.1002/etep.1878

8. Stambouli AB. Algerian renewable energy assessment: the challenge of sustainability. Energy Policy.2011;39(8),4507-4519. https://doi.org/10.1016/i.enpol.2010.10.005

9. Palanichamy C, Babu NS. Analytical solution for combined economic and emissions dispatch. Electr Power Syst Res. 2008;78(7):1129-37. https://doi:10.1016/j.epsr.2007.09.005

10. Adarsh BR, Raghunathan T, Jayabarathi T, Yang X$\mathrm{S}$. Economic dispatch using chaotic bat algorithm. Energy. 2016; 666-75. http://dx.doi.org/10.1016/j.energy.2015.12.096

11. Gwo-Ching L. A novel evolutionary algorithm for dynamic economic dispatch with energy saving and emission reduction in power system integrated wind power. Energy. 2011; 36, 2, 1018-1029. https://doi.org/10.1016/j.energy.2010.12.006

12. Basu M, Chowdhury A. Cuckoo search algorithm for 
economic dispatch. Energy. 2013;113:99-108. http://dx.doi.org/10.1016/j.energy.2013.07.011

13. Si Tayeb, A. Bouzeboudja, H. Application of a New Meta-heuristic Algorithm using Egyptian Vulture Optimization for Economic. PRZEGLAD ELEKTROTECHNICZNY, R. 95 NR 6.2019. http://doi:10.15199/48.2019.06.11

14. He X, Rao Y, Huang J. A novel algorithm for economic load dispatch of power systems. Neurocomputing. 2016; 171(1):1454-61. https://doi.org/10.1016/j.neucom.2015.07.107

15. Basu M. Kinetic gas molecule optimization for nonconvex economic dispatch problem. Int $\mathrm{J}$ Elec Power 2016; 80:325-32. http://dx.doi.org/10.1016/j.ijepes.2016.02.005

16. Slimani L, Bouktir T .Optimal Power Flow Solution of the Algerian Electrical Network using Differential Evolution Algorithm. TELKOMNIKA. 2012; 10,2: 199-210. https:// doi: 10.11591/telkomnika.v10i2.672

17. Arag_on VS, Esquivel SC, Coello Coello CA. An immune algorithm with power redistribution for solving economic dispatch problems. Inform Sciences .2015;295:609-32. http://dx.doi.org/10.1016/j.ins.2014.10.026

18. B Larouci, L Benasla, A Belmadani. Cuckoo Search Algorithm for Solving Economic Power Dispatch Problem with Consideration of Facts Devices. UPB Sci. Bull, Series C. 2017; 79-81. https:// doi: 10.13140/RG.2.2.17880.21766

19. Shaw B, Mukherjee V, Ghoshal SP. Solution of economic dispatch problems by seeker optimization algorithm. Expert Syst Appl. 2012; 39(1):508-519. https://doi.org/10.1016/j.eswa.2011.07.041

20. Zare K, Haque MT, Davoodi E. Solving non-convex economic dispatch problem with valve point effects using modified group search optimizer method. Electr Pow Syst Res. 2012; 84(1):83-9. https://doi.org/10.1016/j.epsr.2011.10.004

21. Secui DC. A modified symbiotic organisms search algorithm for large scale economic dispatch problem with valve-point effects. Energy. 2016; 113:366-84. https://doi.org/10.1016/j.energy.2016.07.056

22. Pradhan M, Roy PK, Pal T. Grey wolf optimization applied to economic load dispatch problems. Int $\mathbf{J}$ Electr Power. 2016; 83:325-334. https://doi.org/10.1016/j.ijepes.2016.04.034

23. Jayabarathi T, Raghunathan $\mathrm{T}$, Adarsh BR, Suganthan PN. Economic dispatch using hybrid grey wolf optimizer. Energy. 2016; 111:630-41. https://doi.org/10.1016/j.energy.2016.05.105

24. Meng A, Li J, Yin H. An efficient crisscross optimization solution to large-scale non-convex economic load dispatch with multiple fuel types and valve-point effects. Energy. 2016; 113:1147-61. https://doi.org/10.1016/j.energy.2016.07.138

25. Dexuan Z, Steven L, Zongyan L, Xiangyong K. A new global particle swarm optimization for the economic emission dispatch with or without transmission losses. Energy Conversion and Management.2017;13945-70. http://dx.doi.org/10.1016/j.enconman.2017.02.035.

26. Secui DC. A new modified artificial bee colony algorithm for the economic dispatch problem. Energy Convers Manage. 2015; 89:43-62. https://doi.org/10.1016/j.enconman.2014.09.034

27. Fraga ES, Yang L, Papageorgiou LG. On the modelling of valve point loadings for power electricity dispatch. Appl Energy. 2012; 91:301-3. https://doi.org/10.1016/j.apenergy.2011.10.001

28. Pothiya S, Ngamroo I, Kongprawechnon W. Ant colony optimisation for economic dispatch problem with non-smooth cost functions. Int J Electr Power Energy Syst. 2010; 32(5):478-87. https://doi.org/10.1016/j.ijepes.2009.09.016

29. Niknam T. Doagou M, H Zeinoddini, Meymand H. A new particle swarm optimization for non-convex economic dispatch. Int $\mathrm{T}$ Electr Energy. 2010; 21(1):656-79. https://doi: 10.1002/etep.468

30. Barisal AK, Prusty RC. Large scale economic dispatch of power systems using oppositional invasive weed optimization. Appl Soft Comput. 2015; 29:122-37. https://doi.org/10.1016/j.asoc.2014.12.014

31. Meng K, Wang HG, Dong Z, Wong KP. Quantuminspired particle swarm optimization for valve-point economic load dispatch. IEEE T Power Syst. 2010; 25(1):215-22. https://doi: 10.1109/TPWRS.2009.2036481

32. Subbraj P,Rengaraij R, Salivahanan S, Senthikumar TR. Particle swarm optimization with modified stochastic acceleration facrors solving large scale economic dispatch problem. Int J Elec Power. 2010; 32:1014-23. https://doi.org/10.1016/j.ijepes.2010.02.003

33. Al-Betar MA, Awadallah MA, Khader AT, Bolaji ALA. Tournament-based harmony search algorithm for non-convex economic load dispatch problem. Appl Soft Comput. 2016; 47:449-59. https://doi.org/10.1016/j.asoc.2016.05.034

34. Dilip K, Nandhini M. Adapting Egyptian Vulture Optimization Algorithm for Vehicle Routing Problem. International Journal of Computer Science and Information Technologies. 2016; 7(3):1199-204.

35. Chiranjib S, Sanjeev S, Anupam S .Egyptian Vulture Optimization Algorithm - A New Nature Inspired Meta-heuristics for Knapsack Problem. IC2IT.2013 ;209:227-37. https://doi.org/10.1007/978-3-64237371-8_26

36. Gaing, Z.-L. Particle swarm optimization to solving the economic dispatch considering the generator constraints. IEEE T Power Sys. 2003 ; (3):1187-95. https://doi: 10.1109/TPWRS.2003.814889

37. Victoire T, Jeyakumar A E. Discussion of particle swarm optimization to solving the economic dispatch considering the generator constraints. IEEE T Power Sys.2004;19(4):2121-23. https://doi: 10.1109/TPWRS.2004.831709

38. Victoire T, Jeyakumar A E. Hybrid PSO-SQP for economic dispatch with valve-point effect. Electr Pow Syst Res. 2004; 71(1):51-59. https://doi:10.1016/j.epsr.2003.12.017

39. Sinha N, Chakrabarti R, Chattopadhyay P K. Evolutionary programming techniques for economic load dispatch. IEEE T Evolut Comput. 2003;7(1):8394. https://doi: 10.1109/TEVC.2002.806788

40. Duman S, güvenç U, yörükeren $\mathrm{N}$. gravitational search algorithm for economic dispatch with valvepoint effects. int rev electr eng. 2010; 5(6):2890-5.

41. Al-Sumait J S, Al-Othman A K, Sykulski J K. Application of pattern search method to power system valve-point economic load dispatch. Int $\mathbf{J}$ Elec Power. 2007; 29(10):720-30. https://doi:10.1016/j.ijepes.2007.06.016

42. Belmadani, A, Benasla L, Rahli M. The dynamic economic dispatch including wind power injection in the western algerian electrical power system. Acta Polytechnica Hungarica. 2011; 8(5), 191-204. 
43. Souag S, Benhamida F. A Dynamic Power System Economic Dispatch Enhancement by Wind Integration Considering Ramping Constraint Application to Algerian Power System. international journal of renewable energy research. 2015; 5, 3 .

44. Yamina A G, Hamid B. Resolution of Economic Dispatch Problem of the Algerian Network using Hybrid Metaheuristic. Electrotehnică, Electronică, Automatică (EEA). 2017; 65(1),91-96.

Received 2021-06-22

Accepted 2021-09-08

Available online 2021-09-13

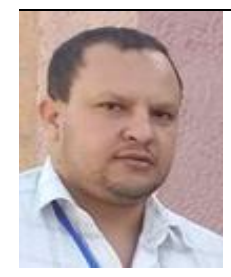

Abdelkader Si TAYEB was born on 05.12.1981.

In 2007, she graduated the Department of Electrotechnic of the Faculty of Electrical Enginnering at University Mascara She defended her master in 2011; she prepared the $\mathrm{PhD}$ degree in Electrical Engineering department of at University (USTO) in Algeria.

Her research activities focusing a practical method based on meta-heuristic for larg scale power system.

Correspondence address: si_tayeb12@yahoo.fr

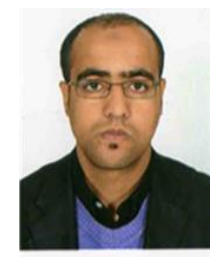

Benyekhlef LAROUCI is a $\mathrm{PhD}$ in Electrical Engineering, was born in 1985 in Mascara, Algeria. $\mathrm{He}$ is currently works at Kasdi Merbah University Ouargla, Algeria. He received a Ph.D degree and Magister in Electricals engineering from the University of Science and technology of Oran, Algeria in 2018. He received a Diploma Engineer in Electrotechnics from the University of Mascara in 2007. His research activities are in the power system optimization problems including economic dispatch, the heuristic optimization techniques and also include the control of large power systems, Facts devices and the unified power flow controller.

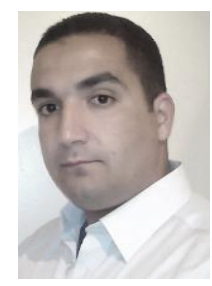

Daoud REZZAK was born in Jijel, Algeria, in 1984. He received the B.Sc. degrees in electrical engineering, from the University of Jijel, Algeria in 2008,theM.Sc. degrees in Electrical Engineering from thePolytechnic Military Academy, Algiers, Algeria in 2011 andthe $\mathrm{PhD}$ degreesin Electrical Engineering, from the University of Jijel, Algeria in 2017.

In 2014, he joined theRenewable Energy Applied Research Unit, Ghardaïa, Algeria, as a Research associate. Since April2021, he is a master research class A.His research interests include power converters design, control technics and energy management in hybrid power systems.

Yehya HOUAM received his Engineer degree in Automatic control from Tebessa University Algeria, in 2006, his Magister of Science (M.Sc) grade and Doctor of Science (Ph.D) grade in Electrical Engineering (Automatic Control) from Biskra University, Algeria, respectively in 2013, and 2021. He is currently a Researcher since 2014 in hybrid energy systems team. Mini Solar power plant division in Unité de Recherche Appliquée en Energies Renouvelables (URAER),
Ghardaïa, Algeria, it is affiliate of Centre de Développement des Energies Renouvelables (CDER), Algiers, Algeria. His research interests include the applications of soft computing (metaheuristic) optimization techniques and power electronics to renewable energy systems (RES), Energy management for autonomous renewable energy systems.

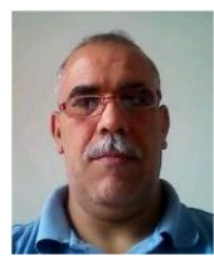

Hami BOUZEBOUDJA was born on 04.03.1965.

In1993 he graduated at the electrotechnical Department of the Faculty of Electrical Engineering at University (USTO) in Algeria.

$\mathrm{He}$ graduated the master in the field optimal power flow problems in 1996.

Presently, he is a Professor in the Electrical Engineering department of USTO, his scientific research is focusing on practical methods based on genetic algorithms for solving the economic dispatch problem of complex systems

Correspondence address : hbouzeboudja@yahoo.fr

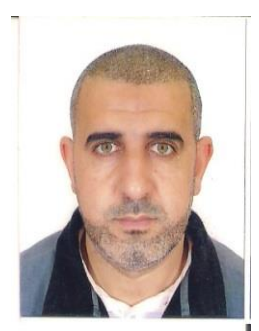

Bouchakour ABDELHAK was born in Algeria in 1984. He obtained his master's degree in electrical engineering, option renewable energies and sustainable development from the University Abdelhalim Ibn Badis in Algeria. Then he obtained his doctoral degree in 2018, in electrical engineering, Option: electrical control from the Univ Djillali liabes of Sidi Belabes.He hold a post of research supervisor $\mathrm{A}$ in an applied research center in renewable energy. 